\title{
Valorization of Seaweed Carbohydrates: Autohydrolysis as a Selective and Sustainable Pretreatment
}

\author{
Joana S. Gomes-Dias, Aloia Romaní, José A. Teixeira, and Cristina M.R. Rocha*
}

Cite This: https://dx.doi.org/10.1021/acssuschemeng.0c05396

ABSTRACT: Seaweeds are promising feedstocks; nevertheless, the lack of systematic approaches to recover different high-value fractions in a clean and sustainable mode hampers their exploitation. Due to this necessity, an innovative environmentally friendly strategy was proposed in this article for the development of a sugar platform from Gelidium sesquipedale: for the first time, autohydrolysis followed by enzymatic saccharification (with cellulolytic and agarolytic cocktails) was applied to agarophyte seaweeds. The wide range of severities (between 2.47 and 4.94) studied in this work proved that the autohydrolysis-based process can be tuned to selectively extract different target carbohydrate

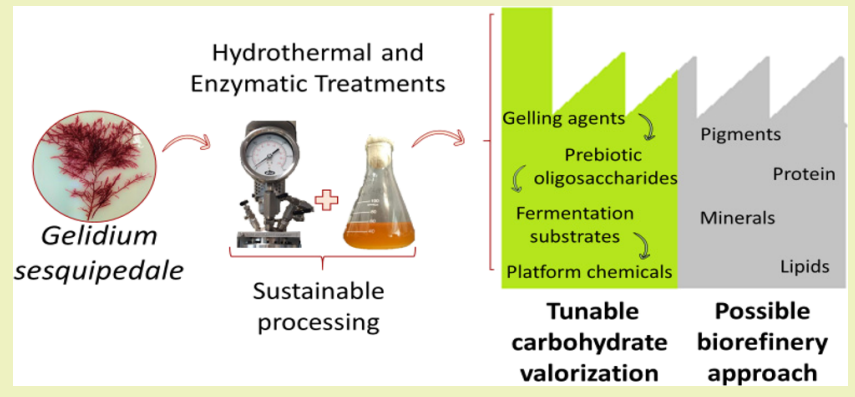
fractions. Gelling agents (reaching $30 \mathrm{~g} / 100 \mathrm{~g} \mathrm{DW}$ ) can be obtained by the application of low severity treatments, fermentable sugars or oligosaccharides with the nutraceutical potential (reaching $14 \mathrm{~g} / 100 \mathrm{~g} \mathrm{DW}$ ) are produced when severity is increased, and at the highest severity, platform chemicals (reaching $4 \mathrm{~g} / 100 \mathrm{~g} \mathrm{DW}$ ) are the final product. The reduction of processing times compared to traditional extraction methodologies and the elimination of chemicals used in dilute acid treatments make this strategy a clean and sustainable alternative for the valorization of both glucan and galactan fractions of G. sesquipedale.

KEYWORDS: Gelidium sesquipedale, hydrothermal pretreatment, sugar platform, macroalgae, sustainable processing, biorefinery

\section{INTRODUCTION}

Macroalgae, also commonly referred to as seaweeds, are carbohydrate-rich organisms. They have the potential to become the center of a marine-based biorefinery, associated with the sustainable production of chemicals, biofuels, biomaterials, or oligosaccharides with functional and nutraceutical capabilities, alongside the valorization of bioactive compounds such as pigments, proteins and peptides, phycobiliproteins, and vitamins. ${ }^{1,2}$ Their advantages over terrestrial biomass include (i) high photosynthetic efficiency, (ii) high mass productivity, (iii) absence of land and fresh water consumption during cultivation, (iv) diminished usage as a primary food source, (v) low cost of collection, and (vi) lack of lignin structures. ${ }^{3,4}$ Moreover, cultivation can be coupled with bioremediation since it can remove heavy metals and nutrients from integrated multitropWhic aquaculture systems and urbanized coastal waters. ${ }^{5,6}$ Recent studies proved that the appropriate cultivation technique combined with bioethanol and biogas production can render the process near total energetic sustainability, while performing bioremediation and eutrophication prevention. ${ }^{7}$ Furthermore, the dewatering of macroalgae at the collection/cultivation site not only reduces the transportation and energy demands of storage but also produces a useful plant biofertilizer. ${ }^{8}$ Thus, the use of this marine resource has several environmental advantages when compared to that of the traditional plant-based lignocellulosic biomass.

Among the red macroalgae, Gelidium is the most associated with high-quality agar for food and biological and pharmaceutical applications. Up to $50 \%$ of the macroalga's cell wall is composed of this structural polysaccharide followed by cellulose (a structural component) and floridean starch (an energetic reserve), making glucose and galactose the major monosaccharides present in this seaweed. ${ }^{1}$ Despite its potential, there are no reports of the integral valorization of this resource in a biorefinery concept, and the majority of treatments are performed using chemicals. ${ }^{9}$ This common technology features operational simplicity, low cost, and short reaction times, but the process is far from ideal due to the rapid formation of known microbial growth inhibitors, alongside its high environmental impact. ${ }^{10,11}$ An enzymatic approach produces no undesired byproducts, but the technology requires a pretreatment to increase the substrate's accessibility to

Received: July 22, 2020

Revised: October 13, 2020 


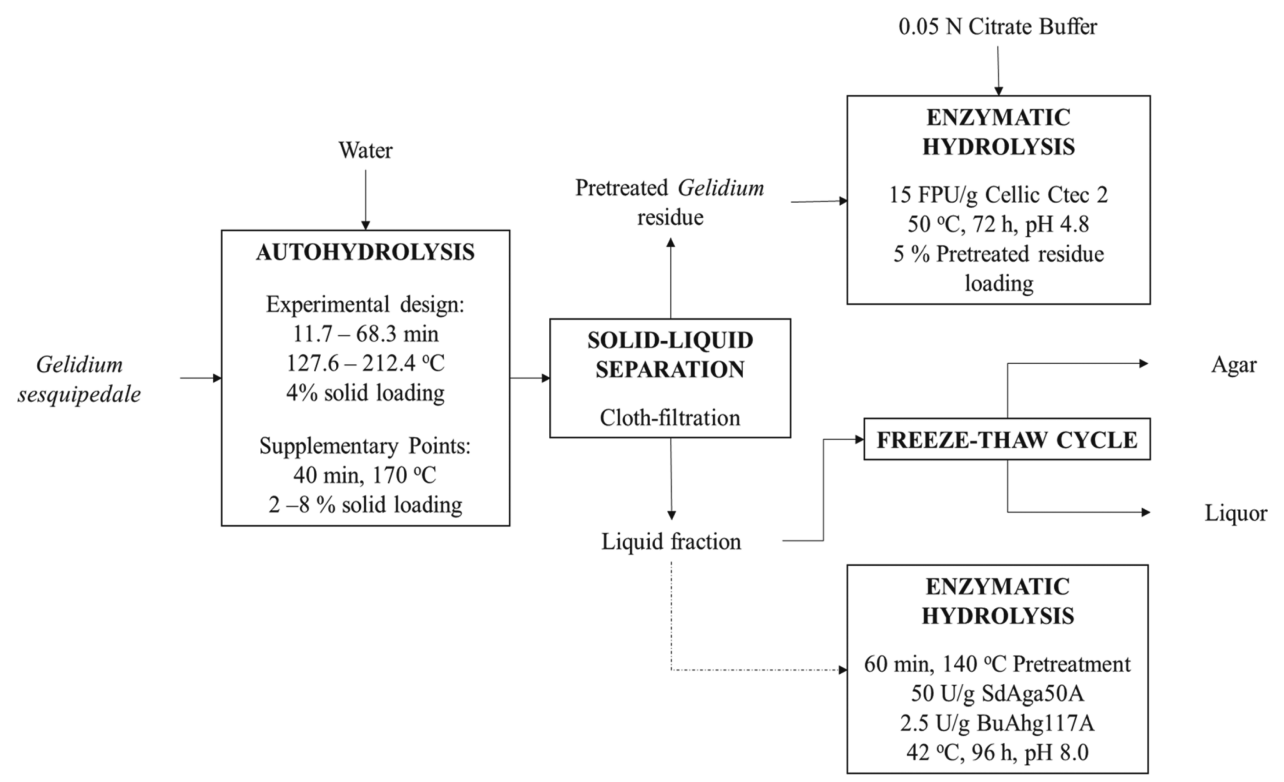

Figure 1. General process workflow.

enzymes and solubility in water. ${ }^{10}$ Moreover, even though some marine polysaccharide-degrading enzymes have been identified and characterized structurally, there are no available commercial mixtures optimized for marine biomass, and the available purified enzymes still have a prohibitive price to allow for large-scale applications. ${ }^{12}$

Thus, hydrothermal processing is a cost-effective and environmentally friendly fractionating technology. At temperatures higher than its boiling point, water is maintained in the liquid state due to the use of pressure superior to its saturated vapor equilibrium pressure. In this state, the dielectric constant increases, significantly increasing affinity toward nonpolar organic hydrocarbons and, due to the higher degree of autoionization, high concentrations of ions are achieved, working as catalysts. ${ }^{3}$ This technology has proven to be effective in the extraction of valuable compounds from several matrixes but, despite its potential, its use in marine biomasses is scarce, with no reports regarding agar-rich red seaweeds. $^{3,4,13-16}$ Therefore, due to its possible operational, environmental, and economic advantages and proven efficiency, autohydrolysis has been considered as the best alternative to fractionate the agarophyte red seaweed Gelidium sesquipedale in an innovative approach.

The aim of this work is to develop hydrothermal pretreatment as a clean technology to be applied as a first step of a seaweed biorefinery through the valorization of the major carbohydrate fraction. The effect of treatment conditions (temperature, time, and seaweed loading) was evaluated on the sugars' recovery (as monosaccharides, oligosaccharides, and polysaccharides) on the hydrolysate (liquid fraction after pretreatment) and pretreated $G$. sesquipedale (remaining solid fraction). Enzymatic saccharification was also performed after pretreatment to obtain fermentable sugars by commercial enzymatic cellulolytic and agarolytic cocktails.

\section{MATERIALS AND METHODS}

Raw Material and Composition Analysis. G. sesquipedale raw biomass used in this study was supplied by Iberagar-Sociedade LusoEspanhola de Colóides Marinhos S.A. (Coina, Portugal). The seaweeds were oven dried at $40{ }^{\circ} \mathrm{C}$ until a moisture content inferior to $10 \%$ was obtained. The dried samples were stored in vacuum sealed bags, at room temperature, in a dry and dark place until their use. Prior to use, all coarse foreign materials were manually removed, and the algae were cut into smaller pieces and washed several times with distilled water to remove the remaining salt and smaller debris.

Raw biomass was analyzed for aqueous and ethanol extractives, ${ }^{17}$ ashes, $^{18}$ structural carbohydrates, ${ }^{19,20}$ lipids, ${ }^{21}$ and proteins ${ }^{22}$ following the standard protocols.

The ash content was determined by calcination in a muffle furnace at $575{ }^{\circ} \mathrm{C}$ until constant weight. Total nitrogen was measured by Kjeldahl digestion, and the protein content was calculated using a conversion factor of $4.59 .^{23}$ The lipid content was determined by extraction with chloroform and methanol. Sequential Soxhlet extractions with (i) distilled water for $16 \mathrm{~h}$ and (ii) $80 \% \mathrm{v} / \mathrm{v}$ ethanol for $8 \mathrm{~h}$ were carried out to remove water-soluble and fat-soluble compounds, respectively. Aliquots from the extractions were subjected to quantitative posthydrolysis $\left(121{ }^{\circ} \mathrm{C}, 20 \mathrm{~min}, 4 \%\right.$ $\mathrm{H}_{2} \mathrm{SO}_{4}$ ) for oligosaccharide determination. The resulting liquid and the extracted liquid were filtered through $0.22 \mu \mathrm{m}$ membranes and analyzed by high-performance liquid chromatography (HPLC) to quantify the solubilized compounds such as glucose, galactose, and hydroxymethylfurfural (HMF). The conditions used in the HPLC analysis were as follows: refractive index detector; Aminex HPX-87H column at $60{ }^{\circ} \mathrm{C}$; and a mobile phase of $0.05 \mathrm{M} \mathrm{H}_{2} \mathrm{SO}_{4}$ at a flow rate of $0.6 \mathrm{~mL} / \mathrm{min}$. Extract-free seaweed was subjected to a two-step quantitative acid hydrolysis (QAH) with (i) $72 \% \mathrm{H}_{2} \mathrm{SO}_{4}, 60 \mathrm{~min}, 30$ ${ }^{\circ} \mathrm{C}$ and (ii) $4 \% \mathrm{H}_{2} \mathrm{SO}_{4}, 60 \mathrm{~min}, 121{ }^{\circ} \mathrm{C}$. The liquid from the QAH was also analyzed by HPLC, using the same conditions as before. Glucan and galactan were calculated from the concentrations of glucose and galactose. The insoluble phase from the QAH was subjected to gravimetric quantitation in number 3 Gooch crucibles and reported as an acid-insoluble residue (AIR). The content of 3,6-anhydrogalactose was determined calorimetrically based on the resorcinol reagent method. ${ }^{24}$ All of the analyses were carried out in triplicate.

Autohydrolysis Pretreatment. The overall process workflow is summarized in Figure 1.

The samples of seaweed $(16 \mathrm{~g})$ were mixed with distilled water $(400 \mathrm{~g})$ in a $1.9 \mathrm{~L} 4520$ Stirred Pressurized Bench Top Reactor (Parr Instruments Company, Moline, Illinois, USA) and subjected to hydrothermal pretreatment according to the experimental design described below, in which temperature and time were chosen as operational variables. The harshness of the hydrothermal treatments $\left(S_{0}\right)$ is often expressed in relation to the severity factor $\left(R_{0}\right)$, combining the effects of temperature and reaction time in a single 
equation and allowing for an easy comparison between experiments carried out under different conditions. ${ }^{3}$ The severity for an isothermal treatment, including heating and cooling, can be calculated by the expression:

$$
\begin{aligned}
& S_{0}=\log R_{0}=\log \left[R_{0_{\text {heating }}}+R_{0_{\text {isothermal }}}+R_{0_{\text {cooling }}}\right] \\
& =\log \left[\int_{0}^{t_{\text {heating }}} e^{T,(t)-T_{\text {ref }} / \omega} \mathrm{d} t+\int_{t_{\text {heating }}}^{t} e^{T-T_{\text {ref }} / \omega} \mathrm{d} t\right. \\
& \left.+\int_{t}^{t_{\text {cooling }}} e^{T \prime \prime(t)-T_{\text {ref }} / \omega} \mathrm{d} t\right]
\end{aligned}
$$

In the aforementioned expression, $R_{0}$ is the severity factor, $t_{\text {heating }}$ is the time (in minutes) necessary to achieve the target temperature $T$ $\left({ }^{\circ} \mathrm{C}\right), t_{\text {cooling }}$ is the time (in minutes) necessary to achieve the final temperature, $T^{\prime}(t)$ and $T^{\prime \prime}(t)$ represent the temperature profiles in the heating and cooling stages, respectively, $T_{\text {ref }}$ is the reference temperature $\left(100{ }^{\circ} \mathrm{C}\right)$, and $\omega$ is an empirical parameter related to the activation energy (14.75 assuming pseudo-first-order kinetics). ${ }^{3,25}$

In addition to time and temperature, the effect of solid loading of Gelidium under a selected condition of hydrothermal treatment (central point, $170^{\circ} \mathrm{C}, 40 \mathrm{~min}$ ) was also evaluated in the range from 2 to $8 \%(\mathrm{w} / \mathrm{w})$.

The medium in the reactor was cooled to $80{ }^{\circ} \mathrm{C}$ after the treatment, and the samples were cloth filtered while hot to prevent the gelling of the medium inside the bioreactor. ${ }^{26}$ The pretreated Gelidium residues were washed, oven dried overnight, and weighed for solubilization yield (SY) determination ( $\mathrm{g}$ solid solubilized/100 g raw material, on a dry basis) and analyzed for chemical composition via $\mathrm{QAH}$. When the gelling of the liquid fraction occurred at ambient temperature (indicating the presence of agar), this liquid fraction was subjected to a freeze and thaw cycle to separate the native agar from the liquor, thus facilitating the operational processing of both fractions and the recuperation of an economically valuable polysacharide. ${ }^{27}$ The former was quantified by weight after dehydration with $96 \%$ ethanol and oven drying at $60{ }^{\circ} \mathrm{C},{ }^{26}$ while the latter was subjected to filtration through $0.22 \mu \mathrm{m}$ membranes and analysis in HPLC, directly for glucose, galactose, and HMF and after QAH for glucooligosaccharide and galactooligosaccharide determination. All of the analyses were carried out, at least, in duplicate.

Experimental Design. The effects of the independent variables, time $\left(X_{1}\right)$, ranging from 11.7 to $68.3 \mathrm{~min}$, and temperature $\left(X_{2}\right)$, ranging from 127.6 to $212.4{ }^{\circ} \mathrm{C}$, on the fractionation of the red seaweed Gelidium were evaluated through a $2^{2}$ central composite design with three replicates at the center point. Experimental runs were randomized to minimize the effects of unexpected variability in the responses.

Solubilization yield (SY, $\left.Y_{1}\right)$, agar $\left(Y_{2}\right)$, glucan content in the residue $\left(\right.$ glucan $\left._{\text {res }}, Y_{3}\right)$, galactan content in the residue $\left(\right.$ galactan $\left._{\text {res }}, Y_{4}\right)$, AIR content in the residue $\left(\mathrm{AIR}_{\mathrm{res}}, Y_{5}\right.$, glucan content in the liquor (glucan $\left._{\text {liq }}, Y_{6}\right)$, galactan content in the liquor $\left(\right.$ galactan $\left._{\text {liq, }}, Y_{7}\right)$, and $\mathrm{HMF}$ in the liquor $\left(\mathrm{HMF}_{\text {liq }}, Y_{8}\right)$ were taken as dependent variables of the experimental design. The correlation between dependent $\left(Y_{n}\right)$ and independent variables $\left(X_{1}\right.$ and $\left.X_{2}\right)$ was established by empirical models following eq 2 :

$$
Y_{\mathrm{n}}=a_{0_{\mathrm{n}}}+a_{1_{\mathrm{n}}} X_{1}+a_{2_{\mathrm{n}}} X_{1}^{2}+a_{3 \mathrm{n}} X_{2}+a_{4_{\mathrm{n}}} X_{2}^{2}+a_{5_{\mathrm{n}}} X_{1} X_{2}
$$

where $Y_{\mathrm{n}}$ is the dependent variable considered (with $n$ ranging from 1 to 8), $a_{0}$ is constant, $a_{1}$ is the linear effect of time, $a_{2}$ is the quadratic effect of time, $a_{3}$ is the linear effect of temperature, $a_{4}$ is the quadratic effect of temperature, and $a_{5}$ is the interaction effects of time and temperature. The regression coefficients were calculated from the experimental data by multiple regression using the least-squares method.

Statistical analysis was conducted to determine significant differences, based on the analysis of variance (ANOVA) using Statistica v. 10 (StatSoft, USA). All $p$-values $<0.05$ were considered as significant. Values are reported as averages with standard deviation. Statistical analyses were conducted between experiments for each parameter and not across parameters.

Enzymatic Saccharification Assays of Pretreated Gelidium Residue. Solids remaining after the autohydrolysis pretreatments were milled and subjected to enzymatic saccharification assays. Tests were performed at a solid loading of $5 \mathrm{~g}$ of pretreated solid to $100 \mathrm{~mL}$ of $0.05 \mathrm{~N}$ citrate buffer $(\mathrm{pH} 4.8)$ and an enzyme to solid ratio of 15 $\mathrm{FPU} / \mathrm{g}^{25}$ to evaluate the effect of pretreatments on enzymatic susceptibility of cellulose. The samples containing the pretreated solid, citrate buffer, and Cellic CTec2 (Novozymes, Denmark) enzymatic cocktail were incubated in an orbital shaker at $50{ }^{\circ} \mathrm{C}$ and $150 \mathrm{rpm}$ for $72 \mathrm{~h}^{28}$ after which the samples were analyzed for glucose and galactose by HPLC. Enzymatic saccharification yield (\%) was calculated based on the glucan to glucose conversion (GGC), presented in eq 3 :

$$
\text { GGC }=\frac{\Delta_{\text {Glucose }}}{\frac{\text { Glucan res }_{\text {res }}}{100} \times \frac{180}{162}}
$$

where $\Delta_{\text {Glucose }}$ is the increase in the glucose concentration $(\mathrm{g} / 100 \mathrm{~g}$ pretreated Gelidium residue, dry weight basis) achieved at the end of the experiment, and the denominator of this fraction represents the potential glucose concentration, where Glucan $_{\text {res }}$ is the glucan content of the pretreated biomass $(\mathrm{g} / 100 \mathrm{~g}$ pretreated Gelidium residue, dry weight basis) and $180 / 162$ is the stoichiometric factor for glucan hydration upon hydrolysis (which represents the molecular weights for glucose in monomeric and polymeric forms, respectively).

Enzymatic Saccharification Assays of Recovered Liquid Phase after Treatment. The assessment of enzymatic saccharification of pretreated galactan was performed in the liquor resulting from run $2\left(140^{\circ} \mathrm{C}, 60 \mathrm{~min}\right)$. The liquid phase recovered directly from the reactor (containing dissolved agar and oligosaccharides) was subjected to an enzymatic treatment with $50 \mathrm{U} / \mathrm{g} \quad \beta$-agarase (SdAga50A) and $2.5 \mathrm{U} / \mathrm{g}$ NABH (BuAhg117A) (Nzytech, Portugal) and incubated at $\mathrm{pH} 8,42{ }^{\circ} \mathrm{C}, 180 \mathrm{rpm},{ }^{29}$ either in combination or in sequential steps ( $\beta$-agarase followed by $\mathrm{NABH}$ at $48 \mathrm{~h}$ incubation). Aliquots were taken over time for HPLC detection of released sugars.

\section{RESULTS AND DISCUSSION}

Raw Material Composition. There is not only a lack of standard protocols optimized for seaweed analysis but also a substantial discrepancy in composition among species, sampling and cultivation sites, growth conditions (temperature, salinity, depth), and cultivation time. ${ }^{4}$ Thus, the complete raw material composition is essential to design processing procedures that allow the full valorization of different biomass types toward a circular economy. In this particular case, a complete polysaccharide characterization is also critical for the overall balance of seaweed fractionation to evaluate the effect of different pretreatments on the recovery of main sugars and to assess the need for further processing, following the biorefinery concept.

As seen in Table 1, polysaccharides are the major component present in G. sesquipedale biomass used in this study. From these, galactan (comprising both galactose and 3,6-anhydrogalactose that constitute agar, averaging $40 \%$ of total biomass) and cellulose (measured as glucan, averaging $15 \%$ of total biomass) were the major sugars detected, which was expected as Gelidium is known as an important agarophyte seaweed, being in concordance with previous values (of $52 \%$ agar and $15 \%$ cellulose) reported. ${ }^{30}$

However, several other monomeric sugars such as rhamnose, xylose, and mannan have been identified in Gelidium sp. biomass and may also be present though always in residual amounts. $^{31}$ From water-extracted galactan, 30\% were determined to be in the form of 3,6-anhydrogalactose. Unfortunately, the majority of papers regarding seaweeds does not 
Table 1. Raw Gelidium sesquipedale Composition

\begin{tabular}{ll}
\multicolumn{1}{c}{ component } & $\mathrm{g} / 100 \mathrm{~g}$ DW \\
ash & $14.78 \pm 0.73$ \\
crude protein & $14.52 \pm 0.09$ \\
crude lipid & $1.47 \pm 0.15$ \\
extractives & \\
water & $28.38 \pm 4.20$ \\
glucan $^{\text {galactan }}{ }^{a}$ & $0.35 \pm 0.01$ \\
ethanol/water $80: 20 \mathrm{v} / \mathrm{v}^{\text {extractive-free residue }}$ & $19.17 \pm 3.72$ \\
glucan & $1.63 \pm 0.27$ \\
galactan & \\
AIR & $14.64 \pm 1.88$ \\
& $18.71 \pm 5.59$ \\
& $1.59 \pm 0.11$
\end{tabular}

${ }^{a} \approx 30 \%$ of galactose-based extractives are in the form of $3,6-$ anhydrogalactose.

identify the polysaccharides present, reporting only the total carbohydrate content (measured by mass difference), impairing data comparison. Regarding the ash (14.8\%) and protein (14.5\%) contents, the obtained results are in concordance with the reported values for this red seaweed, ranging from 4.8 to $30.4 \%$ and 2.7 to $18.1 \%,{ }^{31-34}$ respectively. Lipids are the minor component detected, averaging $1.5 \%$ dry weight, and correspond to the extractives obtained using ethanol.

Evaluation of Pretreatment Conditions on Fractionation. Effect of Time and Temperature. Table 2 shows the chemical composition after pretreatment of liquid and solid phases (expressed as $\mathrm{g}$ of component/100 $\mathrm{g}$ of seaweed).

$S Y\left(Y_{1}\right)$ was chosen as a parameter since it represents the pretreatment's overall efficiency. Agar $\left(Y_{2}\right)$ depicts the extraction of polysaccharides with a high polymerization degree and gelling capacity (native agar). Glucan ${ }_{\text {res }}\left(Y_{3}\right)$, galactan $_{\text {res }}\left(Y_{4}\right)$, and $\operatorname{AIR}_{\text {res }}\left(Y_{5}\right)$ represent the main constituents of the pretreated residue, thus indicating how the treatments affect its composition. Similarly, glucan ${ }_{\text {liq }}\left(Y_{6}\right)$ and galactan $n_{\text {liq }}\left(Y_{7}\right)$ represent the sum of their respective mono and oligosaccharides, detailed in Table 3, thus permitting the understanding of the sugar profiles in the liquid fraction, while $\mathrm{HMF}_{\text {liq }}\left(Y_{8}\right)$ represents the sugar degradation compounds (dehydration of hexoses) formed during the pretreatment.
Table 3. Gelidium sesquipedale Liquor Composition According to Autohydrolysis Severity

\begin{tabular}{|c|c|c|c|c|c|c|}
\hline \multirow[b]{2}{*}{ run } & \multirow{2}{*}{$\frac{\text { severity }}{S_{0}}$} & \multicolumn{5}{|c|}{ liquor composition } \\
\hline & & $\begin{array}{c}\text { glucose } \\
(\mathrm{g} / \mathrm{L})\end{array}$ & $\begin{array}{c}\text { galactose } \\
(\mathrm{g} / \mathrm{L})\end{array}$ & $\begin{array}{c}\text { gluco-OS } \\
(\mathrm{g} / \mathrm{L})\end{array}$ & $\begin{array}{c}\text { galacto-OS } \\
(\mathrm{g} / \mathrm{L})\end{array}$ & $\begin{array}{l}\text { HMF } \\
(\mathrm{g} / \mathrm{L})\end{array}$ \\
\hline 5 & 2.47 & 0.10 & 0.26 & 0.35 & 1.04 & 0.00 \\
\hline 1 & 2.55 & 0.11 & 0.09 & 0.34 & 0.87 & 0.00 \\
\hline 2 & 2.84 & 0.11 & 0.12 & 0.36 & 1.41 & 0.00 \\
\hline 7 & 3.23 & 0.13 & 0.22 & 0.74 & 2.16 & 0.00 \\
\hline 9 & 3.71 & 0.19 & 0.96 & 0.92 & 3.14 & 0.22 \\
\hline 10 & 3.71 & 0.15 & 1.08 & 1.15 & 2.87 & 0.37 \\
\hline 11 & 3.71 & 0.13 & 0.96 & 0.95 & 3.18 & 0.38 \\
\hline 8 & 3.94 & 0.17 & 1.73 & 0.89 & 1.41 & 0.83 \\
\hline 3 & 4.32 & 0.33 & 1.28 & 0.65 & 0.00 & 1.29 \\
\hline 4 & 4.59 & 0.26 & 0.28 & 0.16 & 0.27 & 1.60 \\
\hline 6 & 4.94 & 0.15 & 0.15 & 0.36 & 0.49 & 1.16 \\
\hline
\end{tabular}

The dependent variables were well interpreted by the empirical model, as it can be verified from the fitting parameters listed in Table 4.

The agar yield is inversely correlated with the severity of autohydrolysis, in the experimental range tested, with a maximum extraction yield of $30.9 \mathrm{~g} / 100 \mathrm{~g}$ DW corresponding to a severity of 2.47 (run $5,127.6{ }^{\circ} \mathrm{C}, 40 \mathrm{~min}$ ), resulting in an extraction of more than $75 \%$ of galactan present in the biomass. Supplementary experiments led to a yield of $27.9 \pm$ $1.1 \mathrm{~g} / 100 \mathrm{~g} \mathrm{DW}(70 \%$ of the biomass' galactan) and $34.2 \pm 2.0$ $\mathrm{g} / 100 \mathrm{~g} \mathrm{DW}$ (85\% of the biomass' galactan) using conventional extractions $\left(95^{\circ} \mathrm{C}, 2 \mathrm{~h}\right.$, corresponding to an estimated $S_{0}$ of 1.9) and similar hydrothermal pretreatments $\left(150{ }^{\circ} \mathrm{C}, 25\right.$ min, $S_{0}$ of 2.9), respectively. This may indicate that an optimum maximum exists and that the autohydrolysis treatment can lead to higher agar extraction yields when compared with the conventional extraction. A similar yield of $32.4 \mathrm{~g} / 100 \mathrm{~g}$ DW was reported for Gelidium latifolium using subcritical water $\left(110^{\circ} \mathrm{C}\right.$ for $\left.30 \mathrm{~min}\right)$, compared to a yield of $34.3 \mathrm{~g} / 100 \mathrm{~g} \mathrm{DW}$ for conventional hot water extraction $\left(95^{\circ} \mathrm{C}\right.$ for $6 \mathrm{~h}) .{ }^{35}$ However, direct comparisons are not feasible, as the original seaweed may have different initial agar content. These results show that a hydrothermal treatment can be an interesting green alternative for the extraction of valuable compounds from seaweeds such as agar, while also reducing processing time. On the basis of the results obtained in this

Table 2. Operational Conditions of Autohydrolysis Pretreatment of G. sesquipedale and Corresponding Responses

\begin{tabular}{|c|c|c|c|c|c|c|c|c|c|c|c|}
\hline \multicolumn{3}{|c|}{ operational conditions } & \multirow[b]{2}{*}{ severity } & \multicolumn{8}{|c|}{ responses } \\
\hline & time & temperature & & $S Y$ & agar & glucan $_{\text {res }}$ & galactan $_{\text {res }}$ & $\mathrm{AIR}_{\text {res }}$ & glucan $_{\text {liq }}$ & galactan $_{\text {liq }}$ & $\mathrm{HMF}_{\text {liq }}$ \\
\hline run & $X_{1}(\min )$ & $X_{2}\left({ }^{\circ} \mathrm{C}\right)$ & $\mathrm{S}_{0}$ & $Y_{1}(\%)$ & $\begin{array}{c}Y_{2} \\
(\mathrm{~g} / 100 \mathrm{~g})\end{array}$ & $\begin{array}{c}Y_{3} \\
(\mathrm{~g} / 100 \mathrm{~g})\end{array}$ & $\begin{array}{c}Y_{4} \\
(\mathrm{~g} / 100 \mathrm{~g})\end{array}$ & $\begin{array}{c}Y_{5} \\
(\mathrm{~g} / 100 \mathrm{~g})\end{array}$ & $\begin{array}{c}Y_{6}( \\
\mathrm{g} / 100 \mathrm{~g})\end{array}$ & $\begin{array}{c}Y_{7} \\
(\mathrm{~g} / 100 \mathrm{~g})\end{array}$ & $\begin{array}{c}Y_{8} \\
(\mathrm{~g} / 100 \mathrm{~g})\end{array}$ \\
\hline 5 & $40.0(0.00)$ & $127.6(-1.41)$ & 2.47 & 64.05 & 30.93 & 9.54 & 4.24 & 2.46 & 1.25 & 3.62 & 0.00 \\
\hline 1 & $20.0(-1.00)$ & $140.0(-1.00)$ & 2.55 & 63.59 & 28.35 & 11.03 & 3.96 & 2.65 & 1.26 & 2.64 & 0.00 \\
\hline 2 & $60.0(1.00)$ & $140.0(-1.00)$ & 2.84 & 70.23 & 26.14 & 9.86 & 2.30 & 1.31 & 1.32 & 4.21 & 0.00 \\
\hline 7 & $11.7(-1.41)$ & $170.0(0.00)$ & 3.23 & 74.49 & 15.27 & 8.71 & 1.46 & 10.85 & 2.44 & 6.64 & 0.00 \\
\hline 9 & $40.0(0.00)$ & $170.0(0.00)$ & 3.71 & 77.16 & 0.00 & 8.68 & 1.06 & 11.24 & 3.13 & 11.63 & 0.60 \\
\hline 10 & $40.0(0.00)$ & $170.0(0.00)$ & 3.71 & 75.16 & 0.00 & 9.14 & 1.18 & 13.11 & 3.65 & 11.26 & 1.04 \\
\hline 11 & $40.0(0.00)$ & $170.0(0.00)$ & 3.71 & 76.62 & 0.00 & 8.75 & 0.98 & 12.42 & 3.03 & 11.76 & 1.04 \\
\hline 8 & $68.3(1.41)$ & $170.0(0.00)$ & 3.94 & 76.40 & 0.00 & 7.82 & 0.76 & 10.55 & 3.01 & 9.24 & 2.29 \\
\hline 3 & $20.0(-1.00)$ & $200.0(1.00)$ & 4.32 & 78.32 & 0.00 & 7.31 & 0.65 & 11.04 & 2.82 & 3.95 & 3.57 \\
\hline 4 & $60.0(1.00)$ & $200.0(1.00)$ & 4.59 & 73.44 & 0.00 & 7.64 & 0.74 & 16.63 & 1.25 & 1.61 & 4.44 \\
\hline 6 & $40.0(0.00)$ & $212.4(1.41)$ & 4.94 & 73.86 & 0.00 & 7.41 & 0.39 & 16.12 & 1.47 & 1.81 & 3.23 \\
\hline
\end{tabular}


Table 4. Correlation Coefficients for the Selected Responses and the Corresponding Significance Level

\begin{tabular}{|c|c|c|c|c|c|c|c|c|}
\hline & $Y_{1}$ & $Y_{2}$ & $Y_{3}$ & $Y_{4}$ & $Y_{5}$ & $Y_{6}$ & $Y_{7}$ & $Y_{8}$ \\
\hline$a_{0}$ & $76.31^{a}$ & 0.00 & $8.86^{a}$ & $1.08^{a}$ & $12.26^{a}$ & $3.27^{a}$ & $11.55^{a}$ & 0.89 \\
\hline$a_{1}$ & 0.56 & $-2.98^{c}$ & -0.26 & $-0.32^{a}$ & 0.48 & -0.09 & 0.36 & 0.51 \\
\hline$a_{2}$ & -0.63 & $4.34^{b}$ & -0.15 & 0.07 & -1.30 & -0.37 & $-2.36^{b}$ & 0.28 \\
\hline$a_{3}$ & $3.98^{a}$ & $-12.28^{a}$ & $-1.12^{a}$ & $-1.29^{a}$ & $5.38^{a}$ & 0.22 & -0.48 & $1.57^{a}$ \\
\hline$a_{4}$ & $-3.88^{a}$ & $8.25^{a}$ & -0.04 & $0.67^{a}$ & $-2.00^{b}$ & $-1.05^{a}$ & $-4.98^{a}$ & 0.52 \\
\hline$a_{5}$ & $-2.88^{a}$ & 0.55 & 0.37 & $0.44^{a}$ & 1.73 & -0.41 & -0.98 & 0.22 \\
\hline$R^{2}$ & 0.978 & 0.960 & 0.855 & 0.990 & 0.945 & 0.846 & 0.923 & 0.884 \\
\hline $\mathrm{F}$ & 45.397 & 24.374 & 5.910 & 96.420 & 17.613 & 5.515 & 12.311 & 7.743 \\
\hline
\end{tabular}

work, low severity (2-3) seems to be suitable for the extraction of agar as a gelling agent, although a proper experimental design should be made to assess the optimal conditions for extracting agar while keeping or maximizing its gelling functionality. Furthermore, algae aimed toward the extraction of commercially available agar are often pretreated under alkaline conditions before extraction, and the agar is later submitted to purification steps (such as heat resolubilization and redrying); ${ }^{36}$ hence, these parameters should also be considered.

On the other hand, for $S_{0}>3.23$, no agar was obtained. Nevertheless, an increase in the concentration of monosaccharides and oligosaccharides in the liquid fraction was achieved. Sugar yield (representing the sum of glucose, galactose, oligosaccharides, and native agar dissolved in the liquid phase) reached a maximum of $14.8 \mathrm{~g} / 100 \mathrm{~g}$ DW in the pretreatment at $S_{0}$ of 3.71 (run $170{ }^{\circ} \mathrm{C}, 40 \mathrm{~min}$, central point), corresponding to the solubilization of more than a quarter of initial polysaccharides. Similar results were obtained in the subcritical water extraction of the brown seaweed Fucus vesiculosus, with a maximum sugar yield of $14 \% \mathrm{w} / \mathrm{w}$ obtained when using severities equal to or higher than $3.7^{37}$ and a maximum sugar yield of $10 \mathrm{mg} / \mathrm{g}$ DW Ulva sp. corresponding to a severity of 3.9. ${ }^{38}$ However, an optimal severity of 2.15 regarding the fucoidan yield was reported for Himanthalia elongata. ${ }^{39}$ Once again, these works (as the majority of the literature) do not present the composition of the polysaccharide fractions extracted, focusing only on the hydrolysis yield, making it difficult to establish relations between the different treatments employed. The results presented here show that due to the presence of simpler (thus more easily fermentable) sugars and low concentrations of inhibitory compounds, hydrothermal pretreatment with a severity in the range of 3.2-3.7 is a valuable alternative to the production of substrates for fermentative processes, substituting the traditional chemical route based on diluted acids.

Under hasher conditions of pretreament $\left(S_{0}>3.7\right)$, sugar yield decreases significantly, coupled with an increase in sugar degradation products (with HMF reaching a maximum of 4.4 $\mathrm{g} / 100 \mathrm{~g} \mathrm{DW}$ at the highest severity, corresponding with run 4 $\left.\left(200{ }^{\circ} \mathrm{C}, 60 \mathrm{~min}\right)\right)$. These results are supported by the data published by Kim et al., ${ }^{40}$ which reported a decrease in total reducing sugars for pretreatments with a severity greater than 4.1 due to the overdegradation of polysaccharides extracted from Enteromorpha intestinalis. However, this is a green seaweed, with different main polysaccharides. Therefore, the mechanism toward degradation products may be different and, although the reasoning is valid, the final severity is not comparable. Although HMF is typically considered as a major inhibitor in fermentation processes, it is also considered as an important building block. In fact, it is included in the top 12 of value-added compounds obtained from biomass by the Energy Department of United states, serving as a feedstock for the production of polyesters, liquid alkanes, and other high-interest compounds in fuel and medical fields. ${ }^{41,42}$ Thus, the autohydrolysis treatment at severities higher than 3.7 could be an alternative to chemical catalysis for HMF production. Nevertheless, it is to be noted that in the treatment with the highest severity (4.94), there is an apparent decrease in HMF concentration. This can be explained by the possible transformation of HMF into other degradation compounds such as levulinic and formic acids and even insoluble compounds such as humic-like substances ${ }^{42,43}$ that were unaccounted for in this study. Again, if the final aim is the production of HMF, further optimization would be needed, or further downstream processing should be assessed.

The pretreatment conditions affect not only the overall extraction yield and composition of the extracted fractions but also the type and polymerization degree of the sugars present (Table 3). Monomeric sugars such as galactose, 3,6anhydrogalactose, and glucose are decomposed into HMF at different rates, ${ }^{42,44}$ suggesting that the optimal conditions for maximizing sugar recovery and minimizing the formation of inhibitory compounds depend not only on the pretreatment conditions used but also on the biomass composition. Regarding the glucan fraction, an increase in glucooligosaccharides is observed until a severity of 3.71 is reached, while maximal glucose concentration is reached at a severity of 4.32 . Under more severe conditions, there is a decrease in the overall glucan quantified (measured as glucan present in liquid and solid phases), suggesting a degradation of this compound into HMF and other unidentified compounds accounted for in the $A I R$, with galactan following the same pattern. Even though monomeric sugars are preferential for fermentation, oligosaccharides present advantages for prebiotic use. ${ }^{45}$ The general process for biomass depolymerization in subcritical water implies at least three different steps: conversion of polysaccharides into oligosaccharides, followed by their conversion into monosaccharides, and posterior formation of degradation products. ${ }^{3}$ Since the kinetic constants of the three reactions may be different, with the first step being the rate-limiting step, the simultaneous formation of monomeric sugars and degradation of the already extracted ones is possible. This explains why liquor's contents in monosaccharide and oligosaccharide were not linearly related with the pretreatment's severity.

In a study regarding the environmental impact of several pretreatments for bioethanol production from a terrestrial biomass, Prasad and co-workers concluded that hydrothermal pretreatment had the smallest impact regarding climate change 
(a)

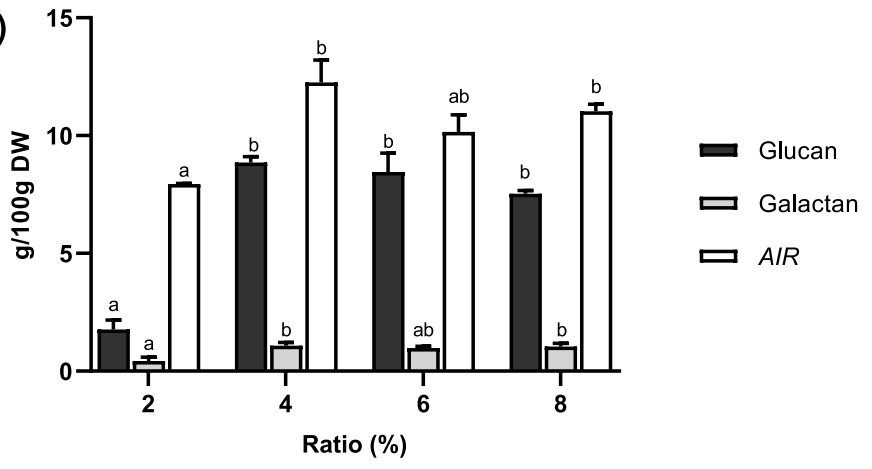

(b)

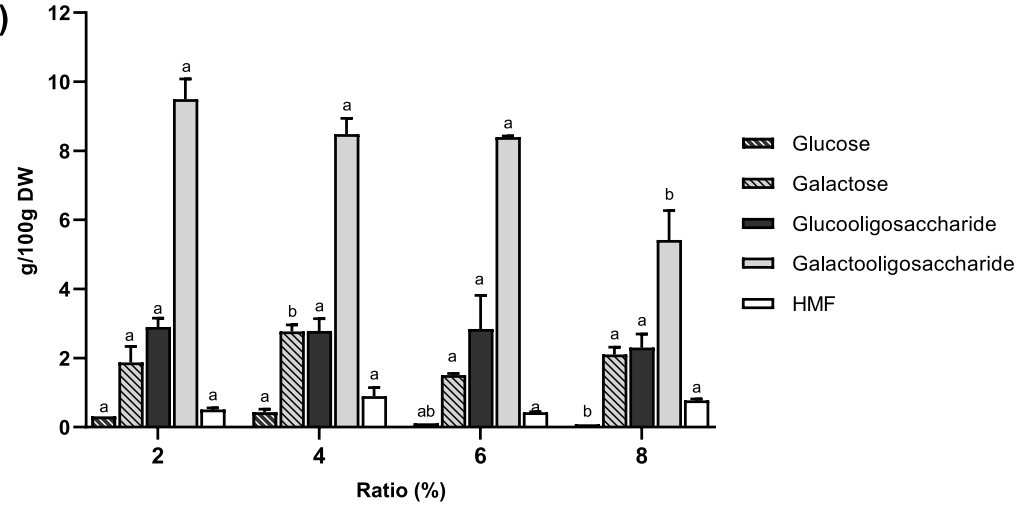

Figure 2. Effect of solid loading on (a) residual macroalgae and (b) extracted liquor composition. Deviation bars correspond to standard deviation $(n=3)$. For the same compound, different letters indicate a statistically significant difference $(p<0.05)$.

(based on carbon dioxide emissions), aquatic eutrophication, and water depletion, performing globally better than dilute acid, steam explosion, and organosolv. ${ }^{46}$ Thus, not only can it reduce processing times and reagent demands, the process is also environmentally friendlier.

Overall, hydrothermal pretreatment has proved to be an efficient alternative to the conventional strategies for marine biomass hydrolysis, allowing the extraction of (i) gelling agents $\left(S_{0} \leq 3.2\right)$, (ii) fermentable sugars with the potential to serve as substrate for fermentation processes $\left(3.2 \leq S_{0} \leq 3.7\right)$, (iii) oligosaccharides with potential nutraceutical use $\left(3.2 \leq S_{0} \leq\right.$ 3.7 ), and (iv) platform chemicals $\left(S_{0} \geq 3.7\right)$.

Considering the condition with the highest sugar concentration in the liquid fraction $\left(170{ }^{\circ} \mathrm{C}, 40 \mathrm{~min}\right)$, nearly $30 \%$ of total polysaccharides were solubilized while inhibitory products reached $0.32 \pm 0.09 \mathrm{~g} / \mathrm{L}$. Thus, this condition was considered to be the most promising, being the one used to evaluate the effect of solid loading.

Effect of Solid Loading. Apart from time and temperature, solid loading is a parameter to consider when optimizing autohydrolysis conditions, since it can lead to an uneven treatment of biomass, ${ }^{3}$ e.g., due to hydrodynamic restrictions inside the reactor. Thus, the effect of solid loading ranging from 2 to $8 \%$ was assessed under the $170{ }^{\circ} \mathrm{C}, 40 \mathrm{~min}$ extraction condition (Figure 2).

An increase in solid loading from 2 to $4 \%$ does not cause any significant interference on the polysaccharide solubilization but is sufficient to affect the composition of the remaining solid, increasing its $A I R$ content and possibly interfering with future uses of this fraction. Moreover, doubling the solid load from 4 to $8 \%$ causes a significant decrease in polysaccharide solubilization from 29 to $20 \%$, linked to a decrease in extracted glucose, galactose, and galactooligosaccharides. Thus, a solid loading of $4 \%$ represents the ideal compromise between the extraction efficiency and the need for further concentration steps. Similar results in the decrease of extracted sugars with the increase of solid loading during hydrothermal pretreatments of marine biomass (green seaweed Ulva sp.) support these findings. ${ }^{38,40}$

Enzymatic Susceptibility. Effect of Pretreatment Conditions on the Enzymatic Saccharification of Residual Biomass. To investigate the effect of the hydrothermal pretreatment conditions on posterior processing steps, the residual solid biomass was hydrolyzed with a cellulase cocktail for $72 \mathrm{~h}$ (Table 5). Glucan enzymatic saccharification efficiency was between $72 \%$ in severe pretreatments $\left(200{ }^{\circ} \mathrm{C}\right.$, $60 \mathrm{~min})$ and $96 \%$ in the milder condition $\left(127.6^{\circ} \mathrm{C}, 40 \mathrm{~min}\right)$, while the galactan present in the residue was not hydrolyzed

Table 5. Effect of Autohydrolysis Conditions on the Enzymatic Saccharification of the Pretreated Gelidium sesquipedale Residue

\begin{tabular}{cccccc}
\multicolumn{3}{c}{ pretreatment } & & \multicolumn{2}{c}{ enzymatic saccharification } \\
\cline { 1 - 3 } \cline { 5 - 6 } run & severity $S_{0}$ & glucan $(\mathrm{g} / 100 \mathrm{~g})^{a}$ & & $\Delta_{\text {Glucose }}(\mathrm{g} / 100 \mathrm{~g})^{a}$ & GGC (\%) \\
5 & 2.47 & 26.55 & & 28.37 & 96.18 \\
1 & 2.55 & 30.30 & & 30.71 & 91.22 \\
2 & 2.84 & 33.11 & & 31.96 & 86.86 \\
7 & 3.23 & 34.12 & & 33.98 & 89.62 \\
9 & 3.71 & 38.02 & & 34.68 & 82.09 \\
10 & 3.71 & 36.79 & & 36.74 & 89.90 \\
11 & 3.71 & 37.41 & & 37.57 & 90.39 \\
8 & 3.94 & 33.12 & & 34.94 & 94.93 \\
3 & 4.32 & 33.74 & & 34.49 & 92.01 \\
4 & 4.59 & 28.75 & & 23.05 & 72.17 \\
6 & 4.94 & 28.33 & & 26.87 & 85.37
\end{tabular}

${ }^{a} \mathrm{~g} / 100 \mathrm{~g}$ pretreated Gelidium residue. 
(galactose was not detected). These high conversion efficiencies imply that almost all of the glucan present in the pretreated Gelidium residue become solubilized (as glucose, available for use as the fermentation substrate) using this simple and cost-effective combination of hydrothermal pretreatment and enzymatic saccharification. Regarding only the cellulose-based fraction of the seaweed, this step increases the glucan solubilization yield from 8 to $24 \%$ obtained in the hydrothermal pretreatment to 54-92\%.

Since it has been proved that enzymatic saccharification is a significant contributor in the majority of impact categories related to bioethanol production (mainly due to the impacts in enzyme production), it is essential to guarantee that this step is optimized so that enzyme loading can be minimized. ${ }^{47}$ Thus, the relevance of an efficient pretreatment and the need for cocktails tailored for marine biomasses are reinforced.

The combination of these strategies results in an overall recovery of total polysaccharides present in the raw biomass of up to $86 \%$ (considering the extracted agar in run 1), leaving only the galactan base of the residue, which can be further valued when enzymatic cocktails tailored for seaweeds become easily available. These results are equal or superior to the ones reported for acid treatment and autoclave pretreatments of the same biomass, ${ }^{34}$ thus reinforcing that hydrothermal pretreatments are a valid alternative to the traditional chemical route.

Feasibility of the Enzymatic Saccharification of Liquefied Biomass. As reported in Table 2, it is not possible to extract significant concentrations of oligomers and monomeric sugars from agar without the degradation products associated. Thus, the option of extracting polymers such as agar and further hydrolyzing them into simpler sugars is as an alternative route, if the final aim is to produce fermentable liquors with a high monosaccharide content. The hydrothermal pretreatment to study the feasibility of an enzymatic saccharification on the extracted liquid fraction was selected based on (i) maximum glucooligosacharides in the liquor, (ii) maximum agar extraction, (iii) maximum solubilization yield, and (iv) minimum formation of inhibitory compounds. Because it presented the ideal compromise between all of the above, the liquid fraction from run $2\left(140{ }^{\circ} \mathrm{C}, 60 \mathrm{~min}\right)$ was hydrolyzed with commercially available agarolytic enzymes (Figure 3 ).

The recombinant $\beta$-agarase employed is reported to hydrolyze agarose into neoagarobiose, which is then further cleaved into galactose and anhydrogalactose by anhydro-Lgalactosidase, implying the necessity of both enzymes for obtaining monosaccharides. ${ }^{48}$ Nonetheless, the maximum saccharification yield was obtained in the first $48 \mathrm{~h}$ of

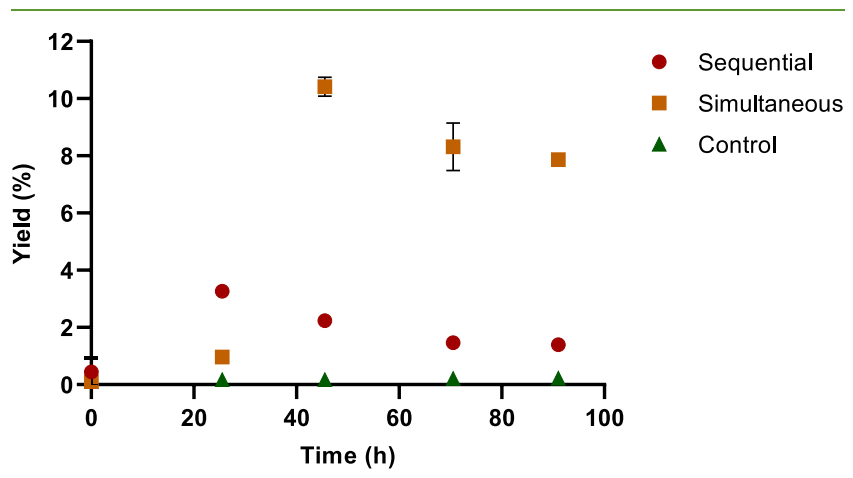

Figure 3. Effect of agarolytic enzymes in the saccharification of liquefied galactan. incubation, a period where only $\beta$-agarase was present in the sequential run. This occurrence had been previously reported by other authors, with similar yields using Aga50A (68\%), in comparison with a mixture of Aga50A and NABH (76\%). ${ }^{49}$

Overall, the sequential process resulted in a higher galactose content than the simultaneous route, possibly due to the formation of odd-numbered oligosaccharides during the depolymerization of agar. ${ }^{50}$

Although the saccharification yield is far from ideal (only $10 \%$ of available galactan was converted to monomers), this study proves that a solvent-free approach for the depolymerization of agar is possible.

Overall Mass Balance. To highlight the optimization results, Figure 4 presents the overall process and mass balance for the most promising conditions. The top half is focused toward the use of the liquid fraction in fermentative processes (high concentration of simple sugars and low concentration of inhibitors), while the bottom half of Figure 4 represents the most promising condition regarding the use of the gelling agents and potential prebiotic effect (high concentration of complex sugars).

It is to be noted that, in the initial biomass composition, the percentage of galactan corresponding to 3,6-anhydrogalactose was dismissed due to its easy degradation, difficulty in quantification and recuperation in the streams, and the inability of most microorganisms in fermenting this monomer. $^{10}$

In this context, after the hydrothermal pretreatment $\left(S_{0}\right.$ of 3.7) followed by enzymatic saccharification, per $100 \mathrm{~g}$ of seaweed $8.6 \mathrm{~g}$ of glucose was obtained in a monosacchariderich HMF-free stream, which could serve as the ideal substrate for fermentative processes. Alongside these, other $3.2 \mathrm{~g}$ of monomeric sugars and $11.3 \mathrm{~g}$ of oligosaccharides were obtained in the liquid fraction, making it suitable either for the nutraceutical use or substrate for fermentation. The integrated process allows for the overall recuperation of 88 and $40 \%$ initial glucan and galactan, respectively. The lack of the recovery of the remaining sugars can be explained by the impossibility to quantify the 3,6-anhydrogalactose present in all of the biomass (due to the method's ability, only the fraction present in the water extractives of the initial biomass was accounted for) and the possible production of additional degradation compounds (such as levulinic and formic acid) that were not quantified.

Similarly, after the hydrothermal pretreatment $\left(S_{0}\right.$ of 2.8$)$, a liquid fraction with $4.9 \mathrm{~g}$ of oligosaccharides was obtained, making it suitable for the nutraceutical use. The gelling fraction, corresponding to the native agar, adds another $18.1 \mathrm{~g}$ of galactans with functional properties (that could be ameliorated with a sodium hydroxide pretreatment of the seaweed to improve the agar's gelling strength and a purification step to remove the impurities from the extracted agar, thus augmenting its market potential). Once again, enzymatic saccharification of the pretreated residue resulted in $9.6 \mathrm{~g}$ of glucose in a fermentable stream. Thus, this approach makes it possible to conjugate the extraction of agar with the production of nutraceuticals and fermentation products, making the best use of the carbohydrate content of the biomass.

Perspectives Regarding a Red Seaweed Biorefinery. With this work, it was proven that autohydrolysis combined with posterior enzymatic treatments can substitute the traditional chemical-based strategy for the saccharification of biomass, 


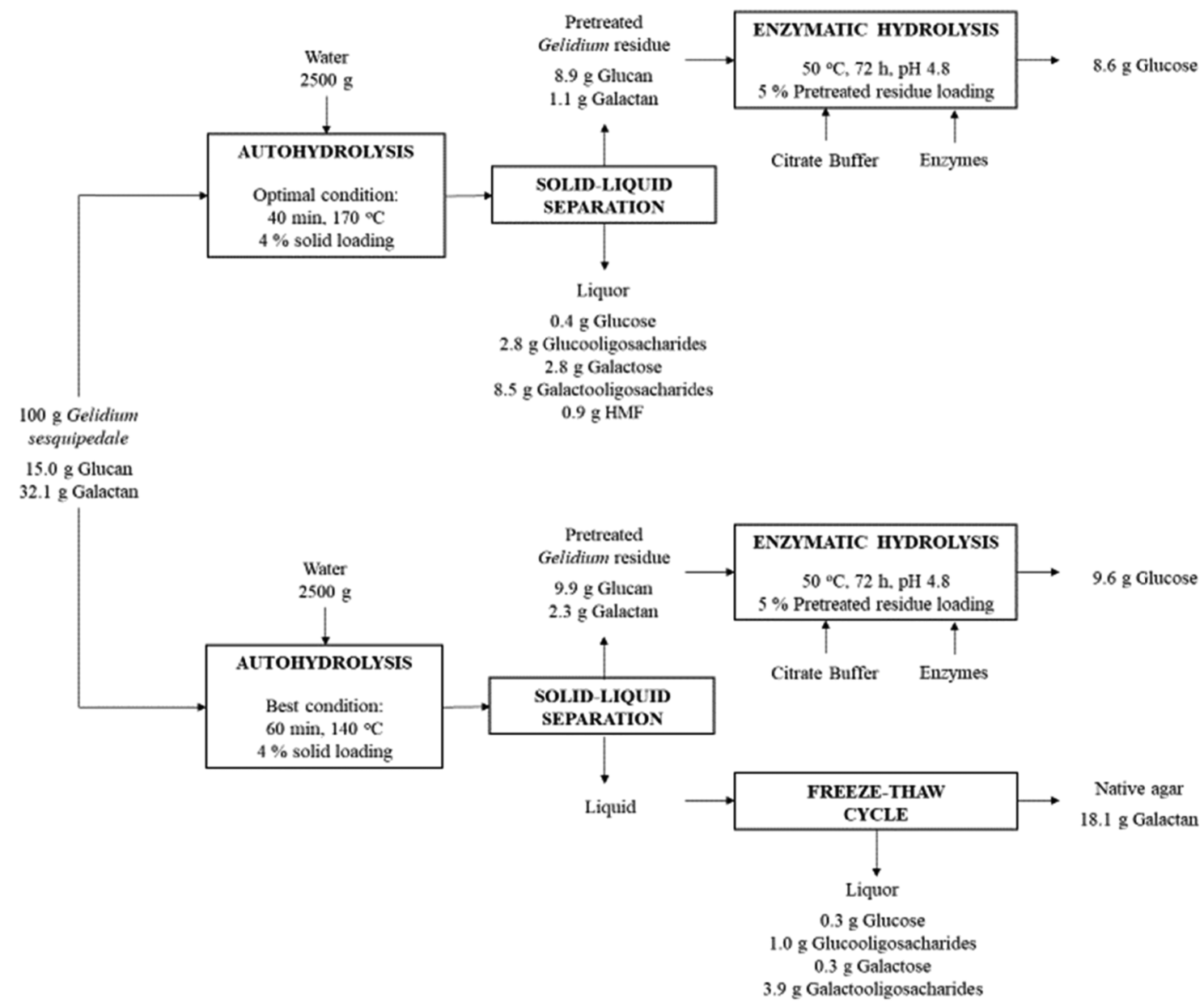

Figure 4. Overall mass balance of the most promising pretreatment regarding fermentative processes (top) and gelling agents/prebiotic potential (bottom).

resulting in several high-value products. This water-based and acid-free approach is greener and thus is more adequate to be employed in a biorefinery approach. Despite this, the work was focused only on the carbohydrate fraction of the biomass, and the minority compounds were not studied. To implement the biorefinery, these fractions require further valorization steps (Figure 5). According to the data presented in the literature, this integral valorization can improve the process metrics in terms of not only its economic value but also its environmental impact. Thus, the use of the mineral-rich fractions is proposed to be used as plant biostimulants, protein fractions can serve as substitutes for animal feed, phenolic compounds and pigments with biological activity can be used as nutraceutical supplements and in cosmetics, and phycobiliproteins have strong cosmetical and biomedical potential, among others. ${ }^{2,8,51,52}$ Furthermore, residual biomass, if significant, can be transformed into biochar, to improve soil fertility, water holding capacity, and remediate contamination. ${ }^{53}$ By combining the biomass cultivation with wastewater treatment plants or fish hatcheries, it is possible to improve the process even further through the recycling of nutrients remaining in otherwise discarded water.

Nevertheless, to fully understand the environmental and economic impacts of the process, further studies need to be conducted, considering all possible final products, cultivation, and treatment conditions, to overcome the enormous information gap regarding marine biomasses.

\section{CONCLUSIONS}

In accordance with the need to reduce the use of chemicals and optimize operations (by reducing reagents and reaction times), autohydrolysis was studied, for the first time, as a pretreatment alternative for agarophyte red seaweeds. The influence of the pretreatment conditions (time, temperature, and solid loading) on the carbohydrate fraction of this marine biomass and its overall impact on further processing steps were described.

Innovatively, it was proven that, by tuning the hydrothermal pretreatment conditions, several products can be obtained from the macroalgae, using no added chemicals, without compromising the overall process yield while guaranteeing the application of a clean process. By making use of and integrating clean technologies, this strategy is the ideal platform for the sustainable production of bioenergy and bioproducts from red macroalgae due to its efficiency, selectivity, and range of outcomes (gelling agents, oligosaccharides, fermentable monomers, and platform chemicals).

The valorization of noncarbohydrate fractions (salts, pigments, lipids, and proteins) and the correct choice of cultivation/harvesting strategies of the biomass can further increase the environmental and economic advantages of the process. Due to their advantages over terrestrial biomasses, the development of protocols and enzymatic cocktails tailored for marine biomasses is expected to be available in the future, rendering their use more interesting from the economic point 

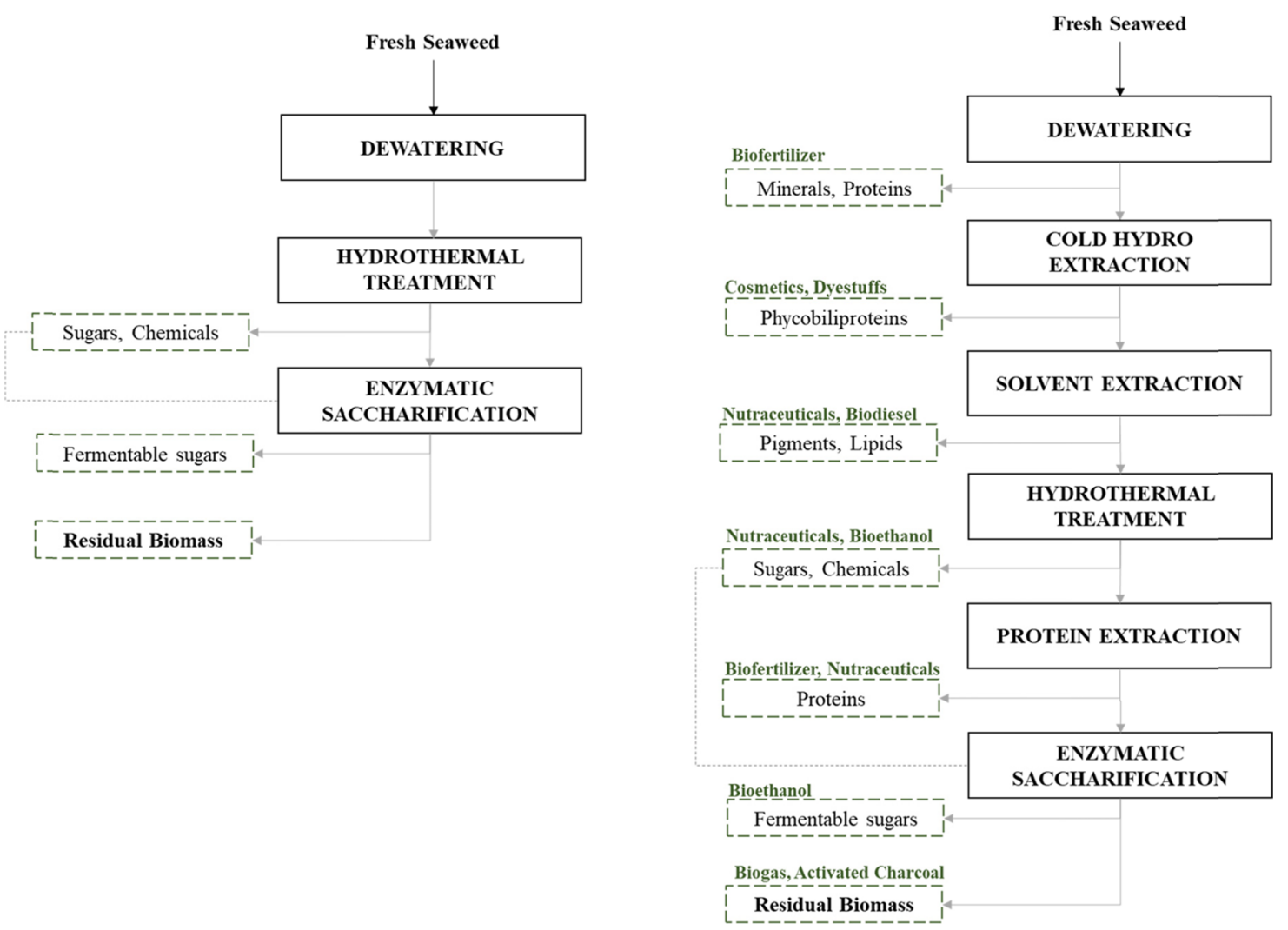

Figure 5. Implemented extraction scheme (left) and the proposed biorefinery-based approach (right).

of view. Further research is recommended to fully understand the industrial feasibility of seaweed usage and its environmental, social, and economic implications.

\section{AUTHOR INFORMATION}

\section{Corresponding Author}

Cristina M.R. Rocha - CEB-Centre of Biological Engineering, University of Minho, Braga 4710-057, Portugal; 다이.org/0000-0003-4687-0266; Email: cmrochainv@ gmail.com

\section{Authors}

Joana S. Gomes-Dias - CEB-Centre of Biological Engineering, University of Minho, Braga 4710-057, Portugal

Aloia Romaní - CEB-Centre of Biological Engineering, University of Minho, Braga 4710-057, Portugal

José A. Teixeira - CEB-Centre of Biological Engineering, University of Minho, Braga 4710-057, Portugal; (1) orcid.org/0000-0002-4918-3704

Complete contact information is available at: https://pubs.acs.org/10.1021/acssuschemeng.0c05396

\section{Notes}

The authors declare no competing financial interest.

\section{ACKNOWLEDGMENTS}

This work was supported by the Portuguese Foundation for Science and Technology (FCT), under the scope of the strategic funding of UID/BIO/04469/2020 unit and under the scope of the project "AlgaePlas-Biorefinery of macroalgae for valorization of the carbohydrate fraction to sustainable bioplastics," PTDC/BII-BIO/29242/2017.

\section{REFERENCES}

(1) Cesário, M. T.; da Fonseca, M. M. R.; Marques, M. M.; de Almeida, M. C. M. D. Marine Algal Carbohydrates as Carbon Sources for the Production of Biochemicals and Biomaterials. Biotechnol. Adv. 2018, 36, 798-817.

(2) Sudhakar, M. P.; Kumar, B. R.; Mathimani, T.; Arunkumar, K. A Review on Bioenergy and Bioactive Compounds from Microalgae and Macroalgae-Sustainable Energy Perspective. J. Clean. Prod. 2019, 228, $1320-1333$.

(3) Ruiz, H. A.; Rodríguez-Jasso, R. M.; Fernandes, B. D.; Vicente, A. A.; Teixeira, J. A. Hydrothermal Processing, as an Alternative for Upgrading Agriculture Residues and Marine Biomass According to the Biorefinery Concept: A Review. Renew. Sustainable Energy Rev. 2013, 21, 35-51.

(4) del Río, P. G.; Gomes-Dias, J. S.; Rocha, C. M. R.; Romaní, A.; Garrote, G.; Domingues, L. Recent Trends on Seaweed Fractionation for Liquid Biofuels Production. Bioresour. Technol. 2020, 299, 122613.

(5) Kim, J. K.; Kraemer, G. P.; Yarish, C. Field Scale Evaluation of Seaweed Aquaculture as a Nutrient Bioextraction Strategy in Long Island Sound and the Bronx River Estuary. Aquaculture 2014, 433, $148-156$.

(6) Abreu, M. H.; Pereira, R.; Yarish, C.; Buschmann, A. H.; SousaPinto, I. IMTA with Gracilaria Vermiculophylla: Productivity and Nutrient Removal Performance of the Seaweed in a Land-Based Pilot Scale System. Aquaculture 2011, 312, 77-87.

(7) Aitken, D.; Bulboa, C.; Godoy-Faundez, A.; Turrion-Gomez, J. L.; Antizar-Ladislao, B. Life Cycle Assessment of Macroalgae Cultivation and Processing for Biofuel Production. J. Clean. Prod. 2014, 75, 45-56.

(8) Baghel, R. S.; Suthar, P.; Gajaria, T. K.; Bhattacharya, S.; Anil, A.; Reddy, C. R. K. Seaweed Biorefinery: A Sustainable Process for Valorising the Biomass of Brown Seaweed. J. Clean. Prod. 2020, 263, 121359 . 
(9) Wei, N.; Quarterman, J.; Jin, Y. S. Marine Macroalgae: An Untapped Resource for Producing Fuels and Chemicals. Trends Biotechnol. 2013, 31, 70-77.

(10) Yun, E. J.; Kim, H. T.; Cho, K. M.; Yu, S.; Kim, S.; Choi, I. G.; Kim, K. H. Pretreatment and Saccharification of Red Macroalgae to Produce Fermentable Sugars. Bioresour. Technol. 2016, 199, 311-318.

(11) Parsons, S.; Allen, M. J.; Abeln, F.; McManus, M.; Chuck, C. J. Sustainability and Life Cycle Assessment (LCA) of MacroalgaeDerived Single Cell Oils. J. Clean. Prod. 2019, 232, 1272-1281.

(12) Siller-Sanchéz, A.; Ruiz, H. A.; Aguilar, C. N.; Rodriguez-Jasso, R. M. Biorefinery Approach for Red Seaweeds Biomass as Source for Enzymes Production: Food and Biofuels Industry. Green Bioprocesses 2019, 413-446.

(13) Herrero, M.; Cifuentes, A.; Ibanez, E. Sub- and Supercritical Fluid Extraction of Functional Ingredients from Different Natural Sources : Plants, Food-by-Products, Algae and Microalgae: A Review. Food Chem. 2006, 98, 136-148.

(14) Jesus, M. S.; Romaní, A.; Genisheva, Z.; Teixeira, J. A.; Domingues, L. Integral Valorization of Vine Pruning Residue by Sequential Autohydrolysis Stages. J. Clean. Prod. 2017, 168, 74-86.

(15) Abdelmoez, W.; Nage, S. M.; Bastawess, A.; Ihab, A.; Yoshida, H. Subcritical Water Technology for Wheat Straw Hydrolysis to Produce Value Added Products. J. Clean. Prod. 2014, 70, 68-77.

(16) Novo, L. P.; Bras, J.; García, A.; Belgacem, N.; Curvelo, A. A. S. Subcritical Water: A Method for Green Production of Cellulose Nanocrystals. ACS Sustainable Chem. Eng. 2015, 3, 2839-2846.

(17) Sluiter, A.; Ruiz, R.; Scarlata, C.; Sluiter, J.; Templeton, D. Determination of Extractives in Biomass. Technical Report NREL/TP510-42619. National Renewable Energy Laboratory: Golden, Colorado, USA 2008.

(18) Sluiter, A.; Hames, B.; Ruiz, R.; Scarllata, C.; Sluiter, J.; Templeton, D. Determination of Ash in Biomass. Technical Report NREL/TP-510-42622. National Renewable Energy Laboratory: Golden, Colorado, USA 2008.

(19) Sluiter, A.; Hames, B.; Ruiz, R.; Scarlata, C.; Sluiter, J.; Templeton, D. Determination of Sugars, Byproducts, and Degradation Products in Liquid Fraction Process Samples. Technical Report NREL/ TP-510-42623. National Renewable Energy Laboratory: Golden, Colorado, USA 2008.

(20) Sluiter, A.; Hames, B.; Ruiz, R.; Scarlata, C.; Sluiter, J.; Templeton, D.; Crocker, D. Determination of Structural Carbohydrates and Lignin in Biomass. Technical Report NREL/TP-510-42618. National Renewable Energy Laboratory: Golden, Colorado, USA 2012.

(21) Bligh, E. G.; Dyer, W. J. A rapid method of total lipid extraction and purification. Can. J. Biochem. Physiol. 1959, 37, 911-917.

(22) Hames, B.; Scarlata, C.; Sluiter, A. Determination of Protein Content in Biomass. Technical Report NREL/TP-510-42625. National Renewable Energy Laboratory: Golden, Colorado, USA 2008.

(23) Lourenco, S. O.; Barbarino, E.; De-paula, J. C.; da Pereira, L. O. S.; Marquez, U. M. L. Amino Acid Composition, Protein Content and Calculation of Nitrogen-to-Protein Conversion Factors for 19 Tropical Seaweeds. Phycol. Res. 2002, 50, 233-241.

(24) Yaphe, W.; Arsenault, G. P. Improved Resorcinol Reagent for the Determination of Fructose, and of 3,6-Anhydrogalactose in Polysaccharides. Anal. Biochem. 1965, 13, 143-148.

(25) Romaní, A.; Tomaz, P. D.; Garrote, G.; Teixeira, J. A.; Domingues, L. Combined Alkali and Hydrothermal Pretreatments for Oat Straw Valorization within a Biorefinery Concept. Bioresour. Technol. 2016, 220, 323-332.

(26) Villanueva, R. D.; Sousa, A. M. M.; Gonçalves, M. P.; Nilsson, M.; Hilliou, L. Production and Properties of Agar from the Invasive Marine Alga, Gracilaria Vermiculophylla (Gracilariales, Rhodophyta). J. Appl. Phycol. 2010, 22, 211-220.

(27) Martínez-Sanz, M.; Gómez-Mascaraque, L. G.; Ballester, A. R.; Martínez-Abad, A.; Brodkorb, A.; López-Rubio, A. Production of Unpurified Agar-Based Extracts from Red Seaweed Gelidium Sesquipedale by Means of Simplified Extraction Protocols. Algal Res. 2019, 38, 101420.
(28) Sukwong, P.; Ra, C. H.; Sunwoo, I. Y.; Tantratian, S.; Jeong, G. T.; Kim, S. K. Improved Fermentation Performance to Produce Bioethanol from Gelidium Amansii Using Pichia Stipitis Adapted to Galactose. Bioprocess Biosyst. Eng. 2018, 41, 953-960.

(29) Weldemhret, T. G.; Nisola, G. M.; Valdehuesa, K. N. G.; Lee, W. K.; Ramos, K. R. M.; Chung, W. J. Ionic Liquid Pretreatment in Tandem with Recombinant Agarase Cocktail Saccharification of Gelidium Amansii for d -Galactose and 3,6-Anhydro- 1 -Galactose Production. ACS Sustainable Chem. Eng. 2019, 7, 7563-7571.

(30) Park, J. H.; Hong, J. Y.; Jang, H. C.; Oh, S. G.; Kim, S. H.; Yoon, J. J.; Kim, Y. J. Use of Gelidium Amansii as a Promising Resource for Bioethanol: A Practical Approach for Continuous Dilute-Acid Hydrolysis and Fermentation. Bioresour. Technol. 2012, 108, 83-88.

(31) Kim, H. M.; Wi, S. G.; Jung, S.; Song, Y.; Bae, H. J. Efficient Approach for Bioethanol Production from Red Seaweed Gelidium Amansii. Bioresour. Technol. 2015, 175, 128-134.

(32) Rabiei, R.; Salleh, A.; Sohrabipour, J.; Ajdari, D. Productivity, Biochemical Composition and Biofiltering Performance of Agarophytic Seaweed, Gelidium Elegans (Red Algae) Grown in Shrimp Hatchery Effluents in Malaysia. Iran. J. Fish. Sci. 2016, 15, 53-74.

(33) Chen, Y. W.; Lee, H. V.; Juan, J. C.; Phang, S. M. Production of New Cellulose Nanomaterial from Red Algae Marine Biomass Gelidium Elegans. Carbohydr. Polym. 2016, 151, 1210-1219.

(34) Ra, C. H.; Jeong, G. T.; Shin, M. K.; Kim, S. K. Biotransformation of 5-Hydroxymethylfurfural (HMF) by Scheffersomyces Stipitis during Ethanol Fermentation of Hydrolysate of the Seaweed Gelidium Amansii. Bioresour. Technol. 2013, 140, 421-425. (35) Ögrretmen, Ö. Y.; Duyar, H. A. The Effect of Different Extraction Methods and Pre-Treatments on Agar Yield and PhysicoChemical Properties of Gelidium Latifolium (Gelidiaceae , Rhodophyta) from Sinop Peninsula Coast of Black Sea, Turkey. J. Appl. Phycol. 2018, 30, 1355-1360.

(36) Rocha, C. M. R.; Sousa, A. M. M.; Kim, J. K.; Magalhães, J. M. C. S.; Yarish, C.; Gonçalves, M. d. P. Characterization of Agar from Gracilaria Tikvahiae Cultivated for Nutrient Bioextraction in Open Water Farms. Food Hydrocolloids 2019, 89, 260-271.

(37) Rodríguez-Jasso, R. M.; Mussatto, S. I.; Pastrana, L.; Aguilar, C. N.; Teixeira, J. A. Extraction of Sulfated Polysaccharides by Autohydrolysis of Brown Seaweed Fucus Vesiculosus. J. Appl. Phycol. 2013, 25, 31-39.

(38) Greiserman, S.; Epstein, M.; Chemodanov, A.; Steinbruch, E.; Prabhu, M.; Guttman, L.; Jinjikhashvily, G.; Shamis, O.; Gozin, M.; Kribus, A.; Golberg, A. Co-Production of Monosaccharides and Hydrochar from Green Macroalgae Ulva (Chlorophyta) Sp . with Subcritical Hydrolysis and Carbonization. Bioenergy Res. 2019, 12, 1090-1103.

(39) Cernadas, H.; Flórez-Fernández, N.; González-Muñoz, M. J.; Domínguez, H.; Torres, M. D. Retrieving of High-Value Biomolecules from Edible Himanthalia Elongata Brown Seaweed Using Hydrothermal Processing. Food Bioprod. Process. 2019, 117, 275-286.

(40) Kim, D. H.; Lee, S. B.; Jeong, G. T. Production of Reducing Sugar from Enteromorpha Intestinalis by Hydrothermal and Enzymatic Hydrolysis. Bioresour. Technol. 2014, 161, 348-353.

(41) Dutta, S.; De, S.; Saha, B. Advances in Biomass Transformation to 5-Hydroxymethylfurfural and Mechanistic Aspects. Biomass Bioenergy 2013, 55, 355-369.

(42) Caes, B. R.; Teixeira, R. E.; Knapp, K. G.; Raines, R. T. Biomass to Furanics: Renewable Routes to Chemicals and Fuels. ACS Sustainable Chem. Eng. 2015, 3, 2591-2605.

(43) Kumar, K.; Pathak, S.; Upadhyayula, S. 2nd Generation Biomass Derived Glucose Conversion to 5-Hydroxymethylfurfural and Levulinic Acid Catalyzed by Ionic Liquid and Transition Metal Sulfate: Elucidation of Kinetics and Mechanism. J. Clean. Prod. 2020, 256, 120292.

(44) Khajavi, S. H.; Kimura, Y.; Oomori, T.; Matsuno, R.; Adachi, S. Degradation Kinetics of Monosaccharides in Subcritical Water. J. Food Eng. 2005, 68, 309-313. 
(45) Cherry, P.; Yadav, S.; Strain, C. R.; Allsopp, P. J.; Mcsorley, E. M.; Ross, R. P.; Stanton, C. Prebiotics from Seaweeds: An Ocean of Opportunity? Mar. Drugs 2019, 17, 1-35.

(46) Prasad, A.; Sotenko, M.; Blenkinsopp, T.; Coles, S. R. Life Cycle Assessment of Lignocellulosic Biomass Pretreatment Methods in Biofuel Production. Int. J. Life Cycle Assess 2016, 21, 44-50.

(47) Soam, S.; Kapoor, M.; Kumar, R.; Gupta, R. P.; Puri, S. K.; Ramakumar, S. S. V. Life Cycle Assessment and Life Cycle Costing of Conventional and Modified Dilute Acid Pretreatment for Fuel Ethanol Production from Rice Straw in India. J. Clean. Prod. 2018, 197, 732-741.

(48) Pathiraja, D.; Lee, S.; Choi, I. G. Model-Based Complete Enzymatic Production of 3,6-Anhydro- 1 -Galactose from Red Algal Biomass. J. Agric. Food Chem. 2018, 66, 6814-6821.

(49) Kim, S. W.; Kim, Y. W.; Hong, C. H.; Lyo, I. W.; Lim, H. D.; Kim, G. J.; Shin, H. J. Recombinant Agarase Increases the Production of Reducing Sugars from HCl-Treated Gracilaria Verrucosa, a Red Algae. Algal Res. 2018, 31, 517-524.

(50) Ramos, K. R. M.; Valdehuesa, K. N. G.; Maza, P. A. M. M.; Nisola, G. M.; Lee, W. K.; Chung, W. J. Overexpression and Characterization of a Novel $\alpha$-Neoagarobiose Hydrolase and Its Application in the Production of D-Galactonate from Gelidium Amansii. Process Biochem. 2017, 63, 105-112.

(51) Seghetta, M.; Hou, X.; Bastianoni, S.; Bjerre, A. B.; Thomsen, M. Life Cycle Assessment of Macroalgal Biorefinery for the Production of Ethanol, Proteins and Fertilizers - A Step towards a Regenerative Bioeconomy. J. Clean. Prod. 2016, 137, 1158-1169.

(52) Zhao, P.; Niu, J.; Huan, L.; Gu, W.; Wu, M.; Wang, G. Agar Extraction from Pyropia Haitanensis Residue after the Removal and Purification of Phycobiliproteins. J. Appl. Phycol. 2019, 31, 24972505.

(53) De Bhowmick, G.; Sarmah, A. K.; Sen, R. Production and Characterization of a Value Added Biochar Mix Using Seaweed, Rice Husk and Pine Sawdust: A Parametric Study. J. Clean. Prod. 2018, 200, 641-656. 